\title{
Foreword: Balneotherapy in rheumatic diseases
}

\section{Antonella Fioravanti ${ }^{1}$}

Published online: 26 May 2020

(C) ISB 2020

Balneotherapy (BT) is one of the most commonly used nonpharmacological complementary therapies for different rheumatic diseases in many European countries, as well as in Turkey, Israel and Japan.

During the past decade, relevant advances have been achieved to understand the therapeutic effects of BT in some musculoskeletal disorders.

The aim of this Special issue entitled "Balneotherapy in Rheumatic Disease" of the International Journal of Biometeorology was to collect new insights about the mechanism of action and the clinical efficacy of BT in rheumatic disorders.

The issue includes six Original Articles, three Reviews and three Short Communications investigating the role of balneotherapic modalities in the prevention, cure and rehabilitation, and/or exploring their possible biological effects.

In a double-blind, randomized, follow-up study, Király et al. (2019) showed that two different mud packs with similar package and physical properties have a favourable effect on knee pain, physical function and quality of life in patients with knee osteoarthritis. The efficacy persists until 3 months after the end of the cycle of treatment.

The effect of natural factors (mineral water and mud) on changes in the functional state of patients with gonarthrosis was investigated by Varzaityte et al. (2019) confirming the beneficial positive and long-lasting effect of BT in osteoarthritis.

Cantista and Maraver (2020) performed a randomized controlled trial in a large sample of patients with knee osteoarthritis treated with 3-week BT intervention. The aims of this study were to identify the possible health benefits (in terms of effects on pain, functionality, emotional and social aspects and quality of life); to assess the clinical relevance of any benefits detected;

Antonella Fioravanti

fioravanti7@virgilio.it

1 Azienda Ospedaliera Universitaria Senese, Siena, Italy and to determine if these effects persist. Improvements were often clinical relevant and in most patients persisted 3 months after treatment onset.

The randomized clinical trial realized by Rapoliene et al. (2019) aimed to investigating the effects of mineral water with different mineral contents on musculoskeletal pain and related symptoms. The Authors showed that mineral water baths are more beneficial than tap water or no treatment for the improvement of symptoms associated with musculoskeletal diseases. Surprisingly, the total mineral content of the water has no significant influence on the reduction of musculoskeletal pain.

The role of the rehabilitation on thermal centers to treat many musculoskeletal disabilities or to recover patients in orthopedic post-surgical period was highlighted by Masiero et al. (2019a, b, 2020) in three different Short Communications.

Neck pain is a very frequent, disabling and costly condition; multiple pharmacological and non-pharmacological interventions are suggested for its treatment. A Systematic Review was performed by Corvillo et al. (2019) to assess the scientific evidence about the role of the aquatic therapy in the treatment of neck pain. The Authors provided a valuable contribution into this subject showing that treatment of neck pain using different waters and techniques is able to reduce pain and disability, and to improve functional capacity, quality of life, joint mobility, balance, relaxation and mood.

Different Authors investigated the complex mechanism of action of mineral waters. In particular, hydrogen sulfide $\left(\mathrm{H}_{2} \mathrm{~S}\right)$, a small gaseous molecule present in sulfurous mineral waters as its active component, caught great attention due to its potential therapeutic applications.

A very interesting contribution comes from Burguera et al. (2019) who showed a reduction of $\mathrm{H}_{2} \mathrm{~S}$ biosynthesis in human cartilage sample from patients with osteoarthritis, supporting the role of sulfurous mineral waters as a valid therapeutic option in this condition.

Furthermore, the Review published by Karagülle and Karagülle (2020) showed a number of biological effects of natural sulfurous water drinking (hydropinotherapy) in studies performed in "in vivo" animal models. 
A large contribution about the role of BT on the innate/ inflammatory responses in osteoarthritis has been provided by Gálvez et al. (2019). The Authors addressed and analyzed the current literature focusing on the effects of mud-bath therapy on several immune, inflammatory and stress mediators. Indeed, the same paper reported the original results obtained on the phagocytic process (chemotaxis, phagocytosis and respiratory or oxidative burst) of circulating monocytes from elderly patients with knee osteoarthritis after a cycle of BT.

Finally, Szabó and Varga (2019) have addressed the unsolved question about the pharmacological effects of organic compounds of mineral natural waters. In this Review, in particular, the Authors analyzed the possible health effects of two organic fractions: benzene and alkylbenzenes and phenolic compounds that might correlate with the therapeutic effect of BT in rheumatological diseases.

The papers published in this special issue cover a wide spectrum of topics providing an overview on current advances or new evidence on the mechanism of action and clinical use of BT in different musculoskeletal disorders.

The Editor hopes that these Articles will help readers update their knowledge about the role of balneotherapy in the treatment of rheumatic diseases.

I would like to thank all who kindly contributed to this Special issue with excellent articles.

Finally, I would like to thank the Editor in Chief, Professor Scott C. Sheridan, and the Managing Editor, Professor Cameron C. Lee, of the International Journal of Biometeorology, for their kind help and cooperation.

\section{References}

Burguera EF, Vela-Anero Á, Gato-Calvo L, Vaamonde-García C, Meijide-Faílde R, Blanco FJ (2019) Hydrogen sulfide biosynthesis is impaired in the osteoarthritic joint. Int J Biometeorol. https://doi. org/10.1007/s00484-019-01823-w

Cantista P, Maraver F (2020) Balneotherapy for knee osteoarthritis in S. Jorge: a randomized controlled trial. Int J Biometeorol. https://doi. org/10.1007/s00484-020-01911-2
Corvillo I, Armijo F, Álvarez-Badillo A, Armijo O, Varela E, Maraver F (2019) Efficacy of aquatic therapy for neck pain: a systematic review. Int J Biometeorol. https://doi.org/10.1007/s00484-01901738-6

Gálvez I, Torres-Piles S, Ortega E (2019) Effect of mud-bath therapy on the innate/inflammatory responses in elderly patients with osteoarthritis: a discussion of recent results and a pilot study on the role of the innate function of monocytes. Int J Biometeorol. https://doi.org/ 10.1007/s00484-019-01748-4

Karagülle MZ, Karagülle M (2020) Effects of drinking natural hydrogen sulfide (H2S) waters: a systematic review of in vivo animal studies. Int J Biometeorol. https://doi.org/10.1007/s00484-019-01829-4

Király M, Kővári E, Hodosi K, Bálint PV, Bender T (2019) The effects of Tiszasüly and Kolop mud pack therapy on knee osteoarthritis: a double-blind, randomised, non-inferiority controlled study. Int $\mathrm{J}$ Biometeorol. https://doi.org/10.1007/s00484-019-01764-4

Masiero S, Litwocenko S, Agostini F, On behalf section of Rehabilitation in Environmental Thermal for Italian Society of Physical Medicine and Rehabilitation (2019a) Rehabilitation in an Italian thermal setting: a new therapeutic strategy for patients with musculoskeletal disability-the results of an Italian survey. Int J Biometeorol. https:// doi.org/10.1007/s00484-019-01765-3

Masiero S, Pignataro A, Piran G, Duso M, Mimche P, Ermani M, Del Felice A (2019b) Short-wave diathermy in the clinical management of musculoskeletal disorders: a pilot observational study. Int J Biometeorol. https://doi.org/10.1007/s00484-019-01806-x

Masiero S, Pranovi G, Di Pumpo M, Bernardini S, Dattilo A, Del Felice A, Sale P (2020) Does aquatic thermal therapy improve quality of life after total hip replacement? A retrospective preliminary pilot study. Int J Biometeorol. https://doi.org/10.1007/s00484-01901846-3

Rapolienè L, Razbadauskas A, Mockevičienė D, Varžaitytė L, Skarbaliené A (2019) Balneotherapy for musculoskeletal pain: does the mineral content matter? Int J Biometeorol. https://doi.org/10. 1007/s00484-019-01800-3

Szabó I, Varga C (2019) Finding possible pharmacological effects of identified organic compounds in medicinal waters (BTEX and phenolic compounds). Int J Biometeorol. https://doi.org/10.1007/ s00484-019-01808-9

Varzaityte L, Kubilius R, Rapoliene L, Bartuseviciute R, Balcius A, Ramanauskas K, Nedzelskiene I (2019) The effect of balneotherapy and peloid therapy on changes in the functional state of patients with knee joint osteoarthritis: a randomized, controlled, single-blind pilot study. Int J Biometeorol. https://doi.org/10.1007/s00484-01901785-z

Publisher's note Springer Nature remains neutral with regard to jurisdictional claims in published maps and institutional affiliations. 